\title{
Study on the Permeability Characteristics of Polyurethane Soil Stabilizer Reinforced Sand
}

\author{
Jin Liu, ${ }^{1}$ Xiaohui Qi, ${ }^{1}$ Da Zhang, ${ }^{1}$ Qiao Feng, ${ }^{1}$ Yong Wang, ${ }^{1}$ and Debi Prasanna Kanungo ${ }^{2}$ \\ ${ }^{1}$ School of Earth Sciences and Engineering, Hohai University, Nanjing 210098, China \\ ${ }^{2}$ CSIR-Central Building Research Institute (CBRI), Roorkee 247667, India
}

Correspondence should be addressed to Jin Liu; jinliu920@163.com

Received 21 January 2017; Revised 28 February 2017; Accepted 6 March 2017; Published 20 April 2017

Academic Editor: Charles C. Sorrell

Copyright (C) 2017 Jin Liu et al. This is an open access article distributed under the Creative Commons Attribution License, which permits unrestricted use, distribution, and reproduction in any medium, provided the original work is properly cited.

A polymer material of polyurethane soil stabilizer (PSS) is used to reinforce the sand. To understand the permeability characteristics of PSS reinforced sand, a series of reinforcement layer form test, single-hole permeability test, and porous permeability test of sand reinforced with PSS have been performed. Reinforcement mechanism is discussed with scanning electron microscope images. The results indicated that the permeability resistance of sand reinforced with polyurethane soil stabilizer is improved through the formation of reinforcement layer on the sand surface. The thickness and complete degree of the reinforcement layer increase with the increasing of curing time and PSS concentration. The water flow rate decreases with the increasing of curing time or PSS concentration. The permeability coefficient decreases with the increasing of curing time and PSS concentration and increases with the increasing of depth in specimen. PSS fills up the voids of sand and adsorbs on the surface of sand particle to reduce or block the flowing channels of water to improve the permeability resistance of sand. The results can be applied as the reference for chemical reinforcement sandy soil engineering, especially for surface protection of embankment, slope, and landfill.

\section{Introduction}

Natural sand material has certain deficiency in the permeability and stability of foundation, slope, and embankment for geotechnical engineering. The materials used in covering on the surface of sand or adding into sand body to reduce or prevent the water permeating into the sand body are mainly geomembrane, geotextile, concrete slab, plant, and so on [1-9]. Ghosh and Yasuhara [1] studied the flow characteristics of geosynthetic drain confined in soils undergoing consolidation. Raisinghani and Viswanadham [3] evaluated the permeability characteristics of a geosynthetic-reinforced soil. Palmeira and Gardoni [4] presented the drainage and filtration properties of nonwoven geotextiles under confinement using different experimental techniques. These materials can improve the permeability resistance and stability of the soil, but the properties of soil are not modified. While the material is moved or damaged, the high permeability or instability of soil will be reverted.
At present, the polymer materials of polyvinyl acetate (PVA), polyurethane, polyacrylamide, and have been considered as the new soil stabilizers to reinforce the soil [10-16]. Kukal et al. [10] studied the water-drop stability of PVAtreated natural soil aggregates from different land uses. Liu et al. [11] presented the polyurethane sand-fixing agent on sand fixation. Inyang and Bae [12] introduced the polyacrylamide sorption opportunity on interlayer and external pore surfaces of contaminant barrier clays. Yang et al. [14] studied the effects of aging tests on a novel chemical sand-fixing agentpolyaspartic acid. Telysheva and Shulga [15] introduced the silicon-containing polycomplexes for protection against wind erosion of sandy soil. Orts et al. [16] proposed the biopolymer additives to reduce erosion-induced soil losses during irrigation. These research results indicated that the polymer materials can improve the strength, water stability, antierosion, and permeability of soil through filling up the soil voids and enwrapping the soil particles.

In this paper, the polyurethane soil stabilizer (PSS) is sprayed on sand surface to form a reinforcement layer, and 


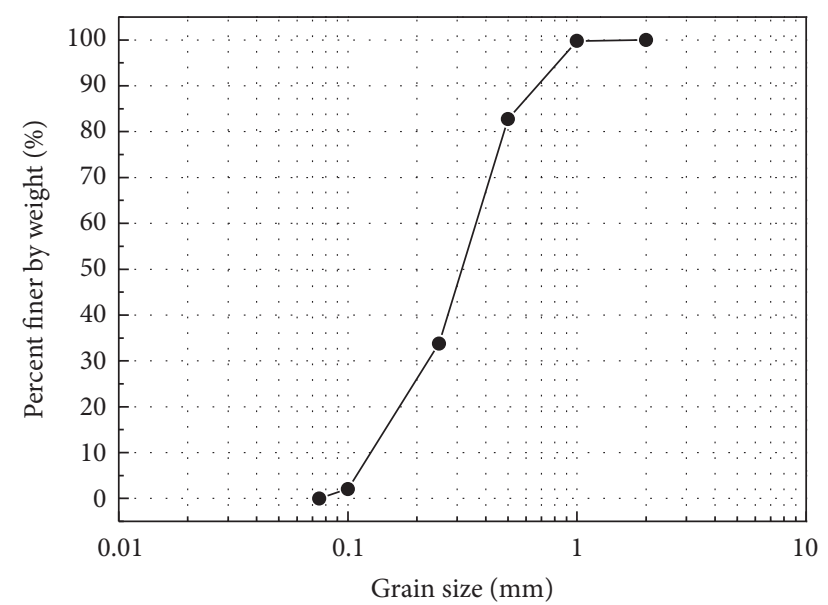

FIGURE 1: Grain size distribution of sand.

the reinforcement layer form test, single-hole permeability test, and porous permeability test are performed in laboratory to analyze the effects of PSS reinforced on sand. Its reinforcement mechanism is discussed with images of scanning electron microscope (SEM). Based on the analyses of interaction between PSS and sand, the optimal curing time and PSS concentrations are suggested. The results can be applied as the reference for PSS reinforced sand engineering, especially for surface protection of embankment, slope, and landfill.

\section{Experimental Outlines}

2.1. Materials. The sand selected from Nanjing City of Jiangsu Province, China, was used in this study. Its particle size distribution is shown in Figure 1. It has a specific gravity (Gs) of 2.64, maximum dry density $\left(\rho_{\max }\right)$ of 1.66 , minimum dry density $\left(\rho_{\min }\right)$ of $1.34 \mathrm{~g} / \mathrm{cm}^{3}$, maximum void ratio $\left(e_{\max }\right)$ of 0.970 , and minimum void ratio $\left(e_{\min }\right)$ of 0.590 . Its particles have a mean grain size $\left(D_{50}\right)$ of $0.30 \mathrm{~mm}$, gradation coefficient $\left(C_{g}\right)$ of 1.13 , and uniformity coefficient $\left(C_{u}\right)$ of 2.77 .

A new type of polyurethane soil stabilizer (PSS) was used in this study (Figure 2). It has a main constituent of polyurethane resin and contains enormous amount of functional group -NCO. PSS is light yellow of oil liquid with a $\mathrm{pH}$ of $6-7$, viscosity of $650-700 \mathrm{mPa} \cdot \mathrm{s}$, specific gravity of $1.18 \mathrm{~g} / \mathrm{cm}^{3}$, solid content of $85 \%$, coagulation time of $30-1800 \mathrm{~s}$, and hold water content of larger than 40 times. The coagulation time decreases with the increase in PSS concentration. The PSS concentrations of $1 \%, 3 \%, 5 \%, 7 \%$, and $9 \%$ used in this study have the coagulation times about $30 \mathrm{~min}, 8 \mathrm{~min}, 6 \mathrm{~min}, 4.5 \mathrm{~min}$, and $3.5 \mathrm{~min}$, respectively. PSS is mainly used for the reinforcement of sandy soil. The sand particle contents of reinforced soil are more than $50 \%$.

PSS has the primary advantages: (a) it reacts with water to form elastic and viscous reinforced layer on soil surface with excellent mechanical property; (b) it is an environmentfriendly product with no additional pollution, and it is a kind of biodegradable water-soluble polymer; (c) it is easy to produce and has a low cost.

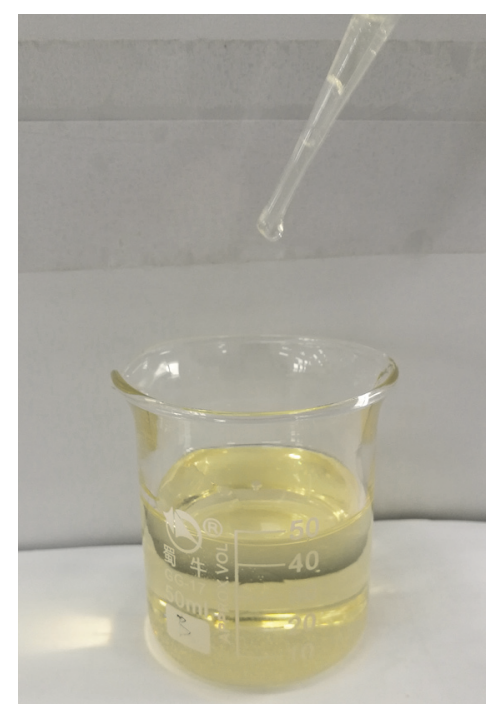

FIGURE 2: Photo of polyurethane soil stabilizer (PSS).

2.2. Experimental Methods. PSS as a soil reinforcement material is sprayed on sand surface to form a reinforcement layer. The initial permeability time and the permeability coefficient of sand are considered as important factors to evaluate the permeability characteristics of sand reinforced with PSS. In this study, the laboratory tests of reinforcement layer form test, single-hole permeability test, and porous permeability test were performed to evaluate permeability characteristics of PSS reinforced sand.

2.2.1. Reinforcement Layer Form Test. The formation of reinforcement layer on sand surface is important to slope surface protection. In reinforcement layer form test, the reinforcement layer thickness of the specimen was measured. Sand specimens taken from slope surface were first oven dried and then filled in a container. The container has a diameter of $10 \mathrm{~mm}$ and height of $6 \mathrm{~mm}$. The dry weight of each specimen was $500 \mathrm{~g}$. Six groups of different concentrations of $0 \%, 1 \%$, $3 \%, 5 \%, 7 \%$, and $9 \%$ of PSS solution and 24 specimens of each group were proposed. The amount $1.6 \mathrm{~L} / \mathrm{m}^{2}$ of each solution was sprayed on the specimen surface uniformly. After spraying, the reinforced specimens were kept in curing box with a temperature around $20^{\circ} \mathrm{C}$, and the reinforcement layer thickness was tested with different curing time of $0 \mathrm{~h}$, $0.1 \mathrm{~h}, 0.5 \mathrm{~h}, 1 \mathrm{~h}, 3 \mathrm{~h}, 6 \mathrm{~h}, 12 \mathrm{~h}$, and $24 \mathrm{~h}$. The block unit of quadrate area $3 \times 3 \mathrm{~cm}$ was taken from the reinforcement layer on specimen surface and its thickness was measured by vernier caliper. Additionally, three specimens were measured for each test and their average values were used.

2.2.2. Single-Hole Permeability Test. In single-hole permeability test, the permeability characteristic of PSS reinforced surface sand was tested by TST-70 permeameter (Figure 3). This apparatus has a top inlet and a bottom outlet tube. The top inlet tube is connected with water tank which keeps a constant head. 


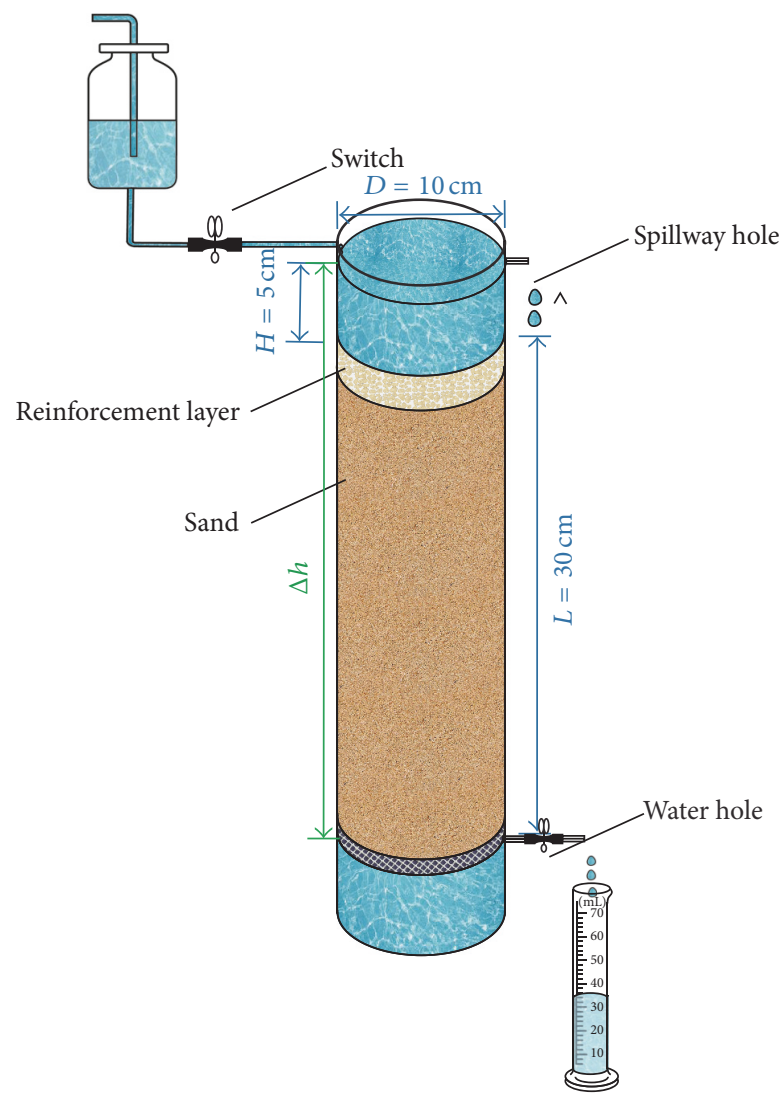

FIGURE 3: TST-70 permeameter used in single-hole permeability tests.

The specimen was directly formed in the testing apparatus. The dry sand was divided into 10 equal parts and each part was put into the box of permeameter and compacted. Specimens for this test with a diameter $10 \mathrm{~cm}$ and a height $30 \mathrm{~cm}$ were prepared in ten layers of equal height to achieve the proposed density $1.44 \mathrm{~g} / \mathrm{cm}^{3}$. After that, six concentrations of $0 \%, 1 \%, 3 \%, 5 \%, 7 \%$, and $9 \%$ of PSS solution were sprayed on sand surface. The amount $1.6 \mathrm{~L} / \mathrm{m}^{2}$ of each solution was sprayed on the specimen surface uniformly. After spraying, the specimens were kept in curing box with a temperature around $20^{\circ} \mathrm{C}$, and the permeability test was carried out with different curing time of $0 \mathrm{~h}, 3 \mathrm{~h}, 6 \mathrm{~h}, 12 \mathrm{~h}$, and $24 \mathrm{~h}$. Firstly, the top inlet and bottom outlet tube were kept open; the water level of specimen surface was maintained. The initial time of water running from specimen surface to the bottom tube was recorded. The running water volume in every 3 minutes was recorded until the water volume difference for successive two times is less than $3 \%$. The average water flow rate for each 3 minutes was given by the following equation [17]:

$$
F=\frac{Q}{\Delta t} .
$$

In (1), $F(\mathrm{ml} / \mathrm{min})$ is defined as the average water flow rate during the designed record time; $Q(\mathrm{ml})$ is water volume during the designed record time interval; $\Delta t$ ( $\mathrm{min}$ ) is the designed record time interval. In this study, the average water flow rate $(F)$ represents the water flow rate of the middle of record time. Therefore, $F$ of record times of $0-3 \mathrm{~min}, 3-6 \mathrm{~min}$, 6-9 $\mathrm{min}, 9-12 \mathrm{~min}$, and $12-15 \mathrm{~min}$ are defined as the water flow rate of test time being $1.5 \mathrm{~min}, 4.5 \mathrm{~min}, 7.5 \mathrm{~min}, 10.5 \mathrm{~min}$, and $13.5 \mathrm{~min}$, respectively.

The permeability coefficient of specimens is obtained by

$$
K=\frac{Q L}{A \Delta h \Delta t} .
$$

In (2), $K(\mathrm{~cm} / \mathrm{s})$ is defined as the permeability coefficient of specimen, $L(\mathrm{~cm})$ is the height of the specimen, $A$ is the cross sectional area of the specimen $\left(\mathrm{cm}^{2}\right)$, and $\Delta h(\mathrm{~cm})$ is water head difference.

The permeability resistance of reinforced specimens was evaluated using

$$
R=\frac{K_{u}}{K_{r}} .
$$

In (3), $R$ is relative permeability resistance of the reinforced sand, $K_{u}$ is permeability coefficient of the unreinforced sand $(\mathrm{cm} / \mathrm{s})$, and $K_{r}$ is permeability coefficient of the PSS reinforced sand $(\mathrm{cm} / \mathrm{s})$. The $R$ values of unreinforced specimens are 1 and the specimens with no water flow are designed as $\infty$. The higher the permeability resistance, the more effective the PSS.

2.2.3. Porous Permeability Test. The permeability resistance of sand with different depth is an effective parameter to evaluate the reinforcement layer. The permeability coefficient of PSS reinforced surface sand with different depth was studied by porous permeability test. In this test, a selfmanufactured permeameter shown in Figure 4 was used. This apparatus with diameter of $20 \mathrm{~cm}$ and height of $100 \mathrm{~cm}$ has 10 outlet tubes in one side. The interval between outlet tubes is $10 \mathrm{~cm}$. The outlet tube number 0 is a spillway hole with a distance of $5 \mathrm{~cm}$ from the top.

The specimen was directly formed in the apparatus. All the tubes were closed at the beginning. The dry sand was divided into 9 equal parts and each part was put into the box of permeameter and compacted. Specimens for this test with a diameter of $20 \mathrm{~cm}$ and a height of $90 \mathrm{~cm}$ were prepared in 9 layers of equal height to achieve the proposed density $1.44 \mathrm{~g} / \mathrm{cm}^{3}$. After that, six concentrations of $0 \%, 1 \%$, $3 \%$, and $5 \%$ of PSS solution were sprayed on sand surface. The amount $1.6 \mathrm{~L} / \mathrm{m}^{2}$ of each solution was sprayed on the specimen surface uniformly. After spraying, the specimens were kept in curing box with a temperature around $20^{\circ} \mathrm{C}$ for $24 \mathrm{~h}$ to form the reinforcement layer. After the specimens were formed, the inlet tube and the outlet tubes numbers 0 and 9 were kept open, and the initial time of water running from specimen surface to the outlet tube number 9 and its running water volume in every 3 minutes were recorded. After that, the operation of close number 9 and open number 8 was performed and its running water volume of every 3 minutes with a number of 5 times was recorded. Then, the outlet tubes numbers 7 to 1 were open in sequence to record their running water volume. It should be noted that only one number of outlet tubes was open to record its running water 


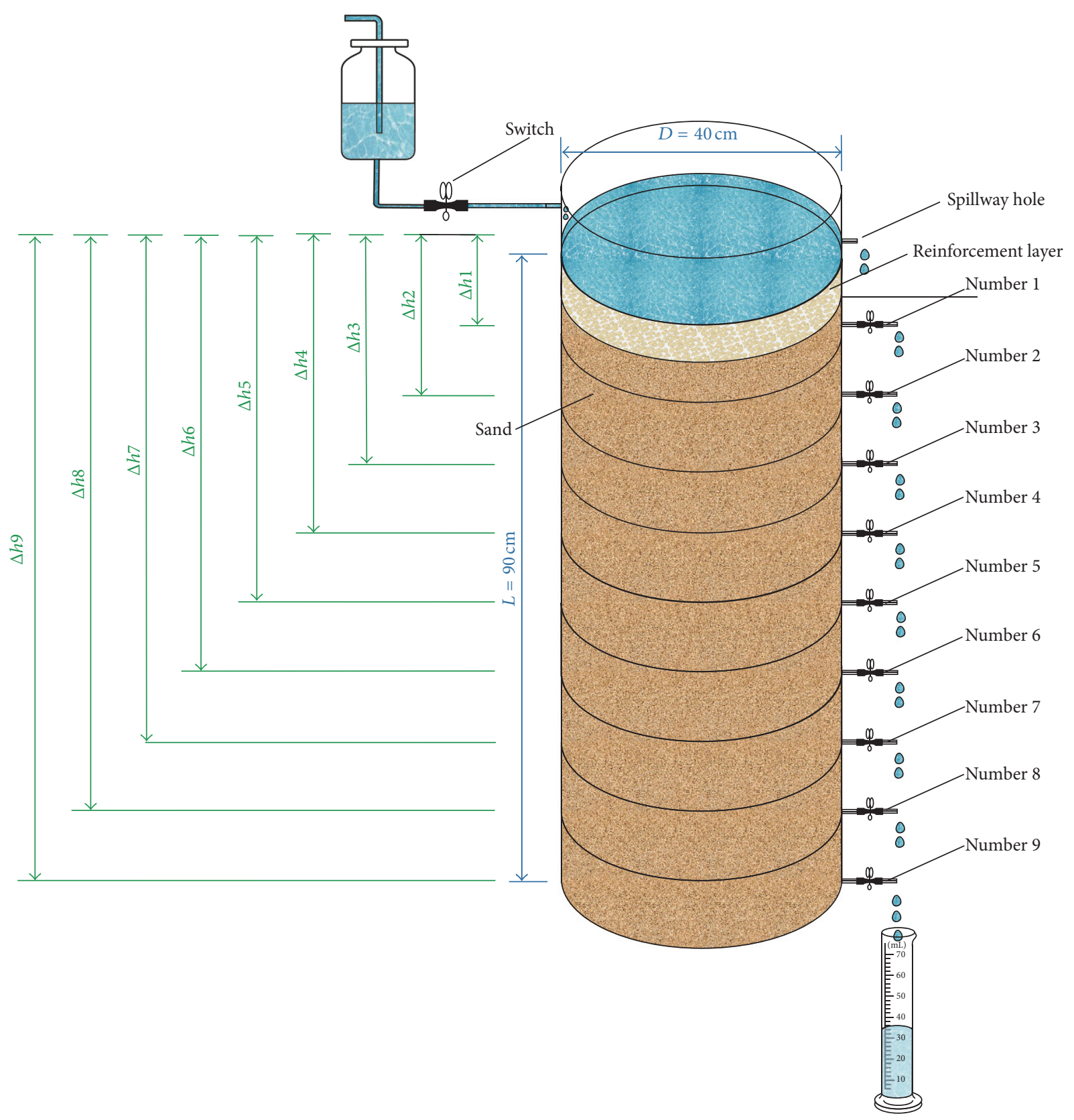

FIGURE 4: Porous permeameter used in porous permeability test.

volume every time. Finally, the initial time of water running from number 9 and the running water volume of number 9 to number 1 were taken to evaluate the permeability resistance of specimens. The data of each outlet tube was recorded until the water volume difference for successive two times is less than $3 \%$. The average water flow rate $(F)$ for each 3 minutes was given by (1). The average water flow rate $(F)$ is also defined as the water flow rate of test time being $1.5 \mathrm{~min}, 4.5 \mathrm{~min}, 7.5 \mathrm{~min}$, $10.5 \mathrm{~min}$, and $13.5 \mathrm{~min}$ for each outlet tube, respectively.

\section{Test Results}

3.1. Reinforcement Layer Form Test. The thickness of reinforcement layer measured with vernier caliper was presented in Figure 5. The results of reinforcement layer form test were presented in Table 1. The reinforcement layer thicknesses of specimens with different curing times are shown in Figure 6.

As seen in Table 1 and Figure 6, with the unreinforced sand as a control specimen it is impossible to form an aggregation due to its little cohesive force. The sand reinforced with PSS $1 \%$ is only able to from a bigger aggregation but not the reinforcement layer. It is different in obtaining an intact reinforcement layer from the specimen surface. The reinforcement layer of specimens reinforced with PSS 3\%, $5 \%, 7 \%$, and $9 \%$ had not been formed without curing. After the specimens curing, the reinforcement layer thickness of treated specimens increased with the increasing of curing 
TABLE 1: The reinforcement layer thickness of samples tested $(\mathrm{cm})$.

\begin{tabular}{lccccccccc}
\hline \multirow{2}{*}{ Number } & \multirow{2}{*}{ PSS concentrations (\%) } & $0 \mathrm{~h}$ & $0.1 \mathrm{~h}$ & $0.5 \mathrm{~h}$ & $1 \mathrm{~h}$ & $3 \mathrm{~h}$ & $6 \mathrm{~h}$ & $12 \mathrm{~h}$ & $24 \mathrm{~h}$ \\
\hline Group 1 & 0 & $/$ & $/$ & $/$ & $/$ & $/$ & $/$ & $/$ \\
Group 2 & 1 & $/$ & $/$ & $/$ & $/$ & $/$ & $/$ & $/$ \\
Group 3 & 3 & $/$ & 0.28 & 0.44 & 0.95 & 1.87 & 2.09 & 2.13 & 2.12 \\
Group 4 & 5 & $/$ & 0.34 & 0.72 & 1.28 & 2.04 & 2.53 & 2.55 & 2.57 \\
Group 5 & 7 & $/$ & 0.45 & 1.15 & 1.56 & 2.54 & 3.00 & 3.02 & 3.05 \\
Group 6 & 9 & $/$ & 0.86 & 1.30 & 1.87 & 2.98 & 3.58 & 3.58 & 3.56 \\
\hline
\end{tabular}

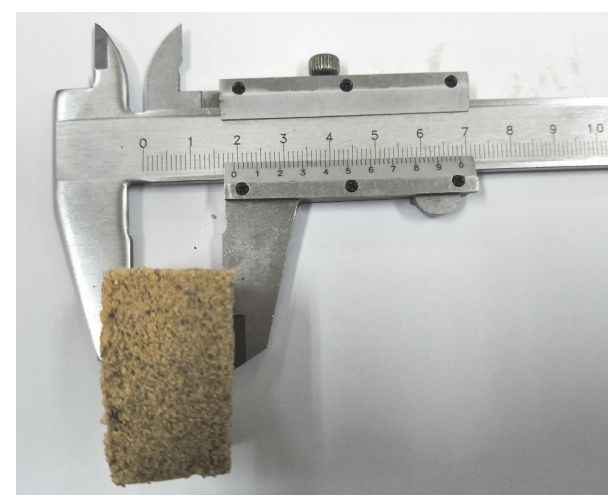

FIGURE 5: Photo of reinforcement layer measured with vernier caliper.

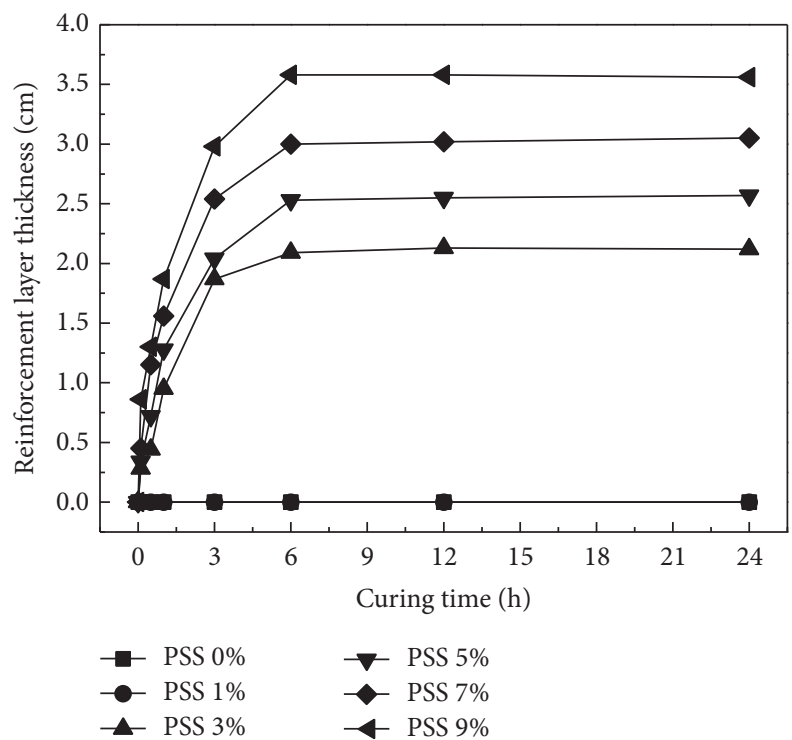

FIGURE 6: The reinforcement layer thickness of specimens with different curing times.

time at the beginning period from curing time 0 to $6 \mathrm{~h}$. Their thickness was kept at a relatively stable value while the curing time was more than $6 \mathrm{~h}$. The reinforcement layer thicknesses of specimens modified by concentration of $3 \%, 5 \%, 7 \%$, and

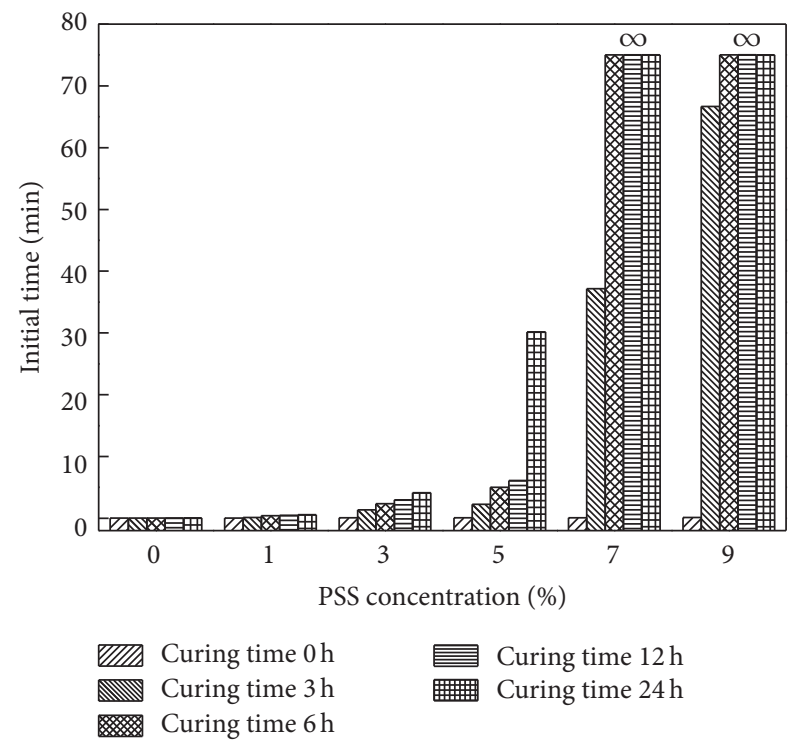

FIGURE 7: Initial time of running water from bottom outlet.

$9 \%$ with curing time of $24 \mathrm{~h}$ were approximately $2.12,2.57$, 3.05 , and $3.56 \mathrm{~cm}$, respectively.

3.2. Single-Hole Permeability Test. In single-hole permeability test, the specimens reinforced with PSS $0 \%, 1 \%, 3 \%, 5 \%$, $7 \%$, and $9 \%$ at curing time of $0 \mathrm{~h}, 3 \mathrm{~h}, 6 \mathrm{~h}, 12 \mathrm{~h}$, and $24 \mathrm{~h}$ were considered. The initial time of water running from the bottom tube and its running water volume of every 3 minutes with a number of 5 times were recorded. The test results are presented in Table 2.

The initial times of running water from bottom tube that is the time of water flowing from top to bottom of specimen are given in Figure 7. As seen in Figure 7, the presence of PSS increased the initial time of specimens. The specimens reinforced with higher PSS concentrations have larger initial times than those reinforced with smaller PSS concentrations. For the specimens unreinforced and reinforced with PSS 1\% and $3 \%$ under different curing times, the water flowed from bottom tube immediately at the beginning of test. With the curing time increasing, the initial time increased, especially for the specimens with PPS 7\% and 9\%. While the curing time is larger than 6 hours, specimens with PPS 7\% and 9\% 
TABLE 2: Results of single-hole permeability test.

\begin{tabular}{|c|c|c|c|c|c|c|c|c|}
\hline Number & $\begin{array}{c}\text { PSS con- } \\
\text { centrations } \\
(\%)\end{array}$ & $\begin{array}{c}\text { Curing time } \\
\text { (h) }\end{array}$ & $\begin{array}{l}\text { Initial time } \\
\text { (s) }\end{array}$ & $\begin{array}{l}\text { Water volume of } \\
0-3 \min (\mathrm{ml})\end{array}$ & $\begin{array}{l}\text { Water volume of } \\
3-6 \mathrm{~min}(\mathrm{ml})\end{array}$ & $\begin{array}{l}\text { Water volume of } \\
6-9 \min (\mathrm{ml})\end{array}$ & $\begin{array}{l}\text { Water volume of } \\
9-12 \min (\mathrm{ml})\end{array}$ & $\begin{array}{l}\text { Water volume of } \\
12-15 \min (\mathrm{ml})\end{array}$ \\
\hline S-1 & 0 & 0 & 2 & 215.35 & 283.34 & 274.67 & 282.57 & 278.85 \\
\hline S-2 & 1 & 0 & 2 & 216.84 & 274.57 & 272.41 & 275.11 & 277.33 \\
\hline S-3 & 3 & 0 & 4 & 115.18 & 120.31 & 110.93 & 147.83 & 147.62 \\
\hline S-4 & 5 & 0 & 5 & 103.92 & 105.97 & 98.54 & 105.41 & 108.54 \\
\hline S-5 & 7 & 0 & 6 & 59.38 & 78.64 & 77 & 80.11 & 83.93 \\
\hline S-6 & 9 & 0 & 8 & 46.63 & 67.8 & 53.01 & 51.51 & 64.59 \\
\hline S-7 & 0 & 3 & 2 & 213.46 & 280.24 & 270.78 & 274.70 & 281.36 \\
\hline S-8 & 1 & 3 & 8 & 145.06 & 161.43 & 168.5 & 160.77 & 160.61 \\
\hline S-9 & 3 & 3 & 82 & 14.35 & 43.69 & 45.17 & 43.96 & 43.57 \\
\hline S-10 & 5 & 3 & 135 & 2.71 & 3.85 & 4.24 & 4.21 & 4.31 \\
\hline S-11 & 7 & 3 & 2230 & 2.28 & 2.39 & 2.22 & 2.14 & 1.91 \\
\hline S-12 & 9 & 3 & 4000 & 0.91 & 1.04 & 1.15 & 1.08 & 1.22 \\
\hline S-13 & 0 & 6 & 3 & 212.16 & 276.84 & 274.45 & 282.42 & 278.58 \\
\hline S-14 & 1 & 6 & 25 & 107.12 & 139.05 & 136.68 & 137.36 & 138.87 \\
\hline S-15 & 3 & 6 & 143 & 11.94 & 38.03 & 41.6 & 40 & 37.48 \\
\hline S-16 & 5 & 6 & 302 & 2.96 & 3.8 & 3.94 & 3.8 & 3.96 \\
\hline S-17 & 7 & 6 & $\infty$ & 0 & 0 & 0 & 0 & 0 \\
\hline S-18 & 9 & 6 & $\infty$ & 0 & 0 & 0 & 0 & 0 \\
\hline S-19 & 0 & 12 & 3 & 215.46 & 281.25 & 275.28 & 281.30 & 278.37 \\
\hline S-20 & 1 & 12 & 27 & 104.32 & 122.08 & 134.74 & 135.66 & 137.07 \\
\hline S-21 & 3 & 12 & 180 & 9.55 & 30.22 & 30.7 & 28.95 & 27.24 \\
\hline S-22 & 5 & 12 & 366 & 2.16 & 3.15 & 3.94 & 3.83 & 3.9 \\
\hline S-23 & 7 & 12 & $\infty$ & 0 & 0 & 0 & 0 & 0 \\
\hline S-24 & 9 & 12 & $\infty$ & 0 & 0 & 0 & 0 & 0 \\
\hline S-25 & 0 & 24 & 3 & 213.27 & 284.56 & 280.35 & 283.35 & 279.47 \\
\hline S-26 & 1 & 24 & 5 & 70.51 & 129.58 & 125.17 & 126.6 & 123.52 \\
\hline S-27 & 3 & 24 & 248 & 7.64 & 13.91 & 13.58 & 14.37 & 13.51 \\
\hline S-28 & 5 & 24 & 1810 & 2.41 & 3 & 3.35 & 3.25 & 3.38 \\
\hline S-29 & 7 & 24 & $\infty$ & 0 & 0 & 0 & 0 & 0 \\
\hline S-30 & 9 & 24 & $\infty$ & 0 & 0 & 0 & 0 & 0 \\
\hline
\end{tabular}

formed a water-resisting layer on surface to prevent the water infiltration.

Based on the data of water volumes in Table 2, the water flow rates $(F)$ of specimens reinforced using different PSS concentrations are calculated with (1) and presented in Figure 8. It can be seen from Figure 8 that the $F$ values of specimens reinforced with PSS are affected strongly by curing time and decrease with the curing time increasing, especially for the ones reinforced with higher PSS concentrations. While the curing time is $0 \mathrm{~h}$ (see Figure $8(\mathrm{a})$ ), the $F$ values of specimens increase with the flow time and then trend to relatively stable values, and the ones unreinforced and reinforced with PPS $1 \%$ have higher $F$ values. As shown in Figures $8(\mathrm{~b})-8(\mathrm{~d})$, the $F$ values of specimens with PSS 5\%, 7\%, and $9 \%$ are negligible. The $F$ values of specimens reinforced with PSS $0 \%, 1 \%$, and $3 \%$ increase with the water flow time at the start period of 0-6 min; after that, it approximately trends to be stable. But all the unreinforced specimens as reference ones kept the same change trend during the different curing times. It also can be seen from Figure 8 that the $F$ values of specimens at the same curing time reduce with the increasing of PSS concentration. And all the specimens reach a stable flow rate at the stage of $12-15 \mathrm{~min}$, and their $F$ values are considered as parameters to evaluate the permeability resistance of specimens reinforced with PSS.

The variations of water flow rate $(F)$ of specimens with PSS concentrations at flow time of $12-15 \mathrm{~min}$ are presented in Table 3 and Figure 9. As seen, the $F$ values of specimens reduce with the increasing in PSS concentration. While the curing time is larger than 3 hours, the $F$ values of specimens reinforced with lower PSS concentrations reduce rapidly. The water flow of specimens with higher PSS concentrations of 
TABLE 3: The evaluation parameters of specimens with different curing times in single-hole permeability tests.

\begin{tabular}{|c|c|c|c|c|c|c|c|c|c|c|c|c|c|c|c|}
\hline \multirow[t]{2}{*}{$\begin{array}{l}\text { PSS } \\
(\%)\end{array}$} & \multicolumn{5}{|c|}{$\begin{array}{l}(F) \text { water flow rate at time } \\
12-15 \mathrm{~min} \\
(\mathrm{ml} / \mathrm{min})\end{array}$} & \multicolumn{5}{|c|}{$\begin{array}{l}(K) \text { permeability coefficient } \\
(\mathrm{cm} / \mathrm{s})\end{array}$} & \multicolumn{5}{|c|}{$\begin{array}{l}(R) \text { relative permeability } \\
\text { resistance }\end{array}$} \\
\hline & $0 \mathrm{~h}$ & $3 \mathrm{~h}$ & $6 \mathrm{~h}$ & $12 \mathrm{~h}$ & $24 \mathrm{~h}$ & $0 \mathrm{~h}$ & $3 \mathrm{~h}$ & $6 \mathrm{~h}$ & $12 \mathrm{~h}$ & $24 \mathrm{~h}$ & $0 \mathrm{~h}$ & $3 \mathrm{~h}$ & $6 \mathrm{~h}$ & $12 \mathrm{~h}$ & $24 \mathrm{~h}$ \\
\hline 0 & 92.95 & 93.79 & 92.86 & 92.79 & 93.16 & $1.69 E-2$ & $1.71 E-2$ & $1.69 E-2$ & $1.69 E-2$ & $1.70 E-2$ & 1 & 1 & 1 & 1 & 1 \\
\hline 1 & 92.44 & 53.54 & 46.29 & 45.69 & 41.17 & $1.68 E-2$ & $9.74 E-3$ & $8.42 E-3$ & $8.31 E-3$ & $7.49 E-3$ & 1.01 & 1.75 & 2.01 & 2.03 & 2.26 \\
\hline 3 & 49.21 & 14.52 & 12.49 & 9.08 & 4.50 & $8.96 E-3$ & $2.64 E-3$ & $2.27 E-3$ & $1.65 E-3$ & $8.19 E-4$ & 1.89 & 6.46 & 7.43 & 10.22 & 20.70 \\
\hline 5 & 36.18 & 1.44 & 1.32 & 1.30 & 1.13 & $6.58 E-3$ & $2.62 E-4$ & $2.40 E-4$ & $2.37 E-4$ & $2.06 E-4$ & 2.57 & 65.13 & 70.35 & 71.38 & 82.44 \\
\hline 7 & 27.98 & 0.64 & 0 & 0 & 0 & $5.09 E-3$ & $1.16 E-4$ & 0 & 0 & 0 & 3.32 & 146.55 & $\infty$ & $\infty$ & $\infty$ \\
\hline 9 & 21.53 & 0.41 & 0 & 0 & 0 & $3.92 E-3$ & $7.46 E-5$ & 0 & 0 & 0 & 4.32 & 228.76 & $\infty$ & $\infty$ & $\infty$ \\
\hline
\end{tabular}

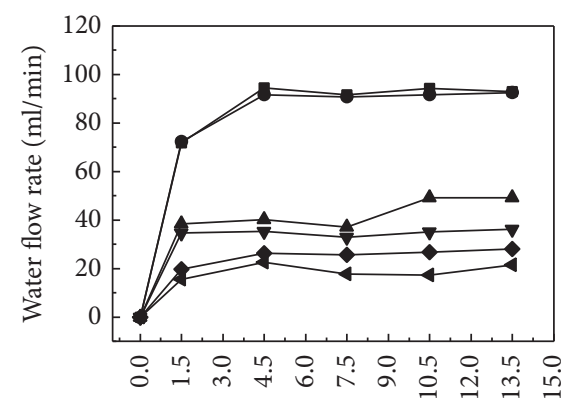

Water flow time (min)

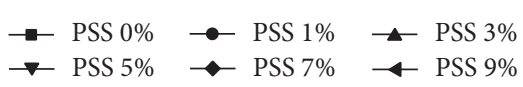

(a) $0 \mathrm{~h}$

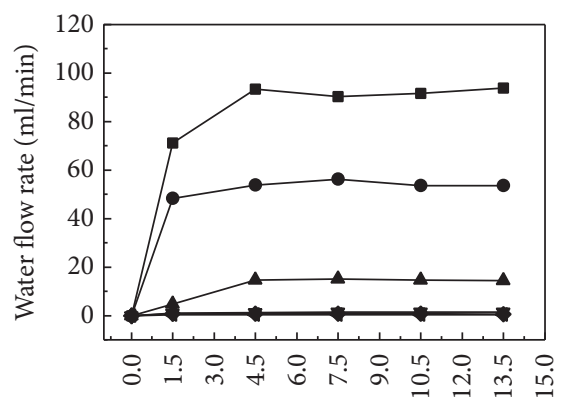

Water flow time (min)

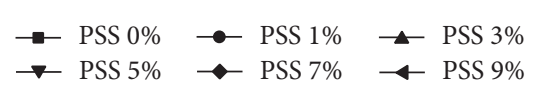

(b) $3 \mathrm{~h}$

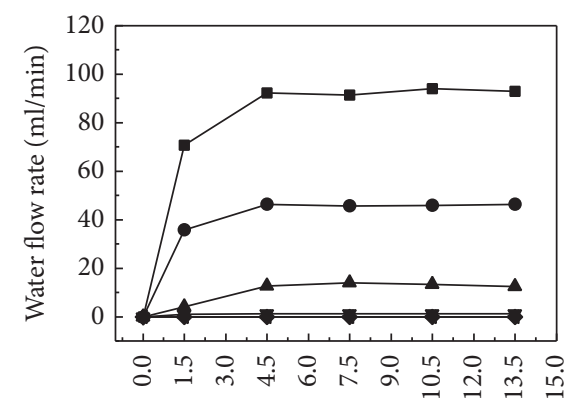

Water flow time (min)

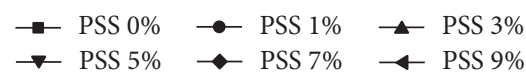

(c) $6 \mathrm{~h}$

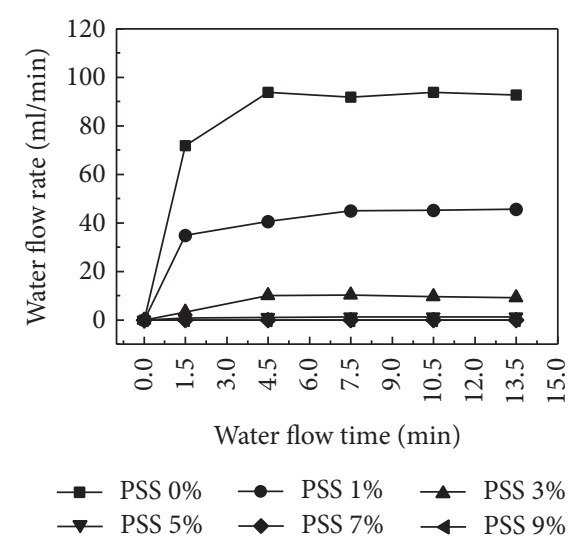

(d) $12 \mathrm{~h}$

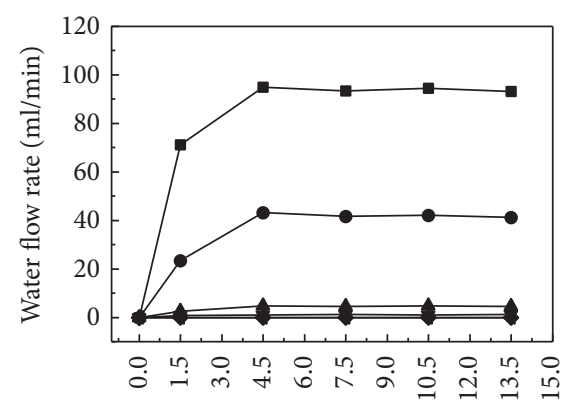

Water flow time (min)

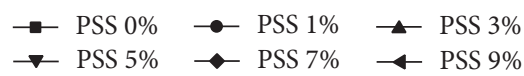

(e) $24 \mathrm{~h}$

FIGURE 8: Water flow rate $(F)$ of specimens reinforced using different PSS concentrations at (a) curing time of $0 \mathrm{~h}$ (b), curing time of $3 \mathrm{~h}$, (c) curing time of $6 \mathrm{~h},(\mathrm{~d})$ curing time of $12 \mathrm{~h}$, and (e) curing time of $24 \mathrm{~h}$.

$7 \%$ and $9 \%$ with curing time larger than 6 hours cannot be recorded and their $F$ values are $0 \mathrm{ml} / \mathrm{min}$ due to the waterresisting layer on the surface of specimens. The permeability coefficients $(K)$ of specimens calculated with (2) are shown in Table 3. They have the same change characteristics with the $F$ values.

The relative permeability resistance $(R)$ calculated with (3) is shown in Table 3 . The $R$ values of specimens with PSS concentrations of $1 \%, 3 \%$, and $5 \%$ at different curing times are presented in Figure 10. As seen, the relative permeability resistances of all reinforced specimens with curing time 0 hours are not improved. The $R$ values of the ones with curing times larger than 3 increase with the PSS concentrations, especially for the specimens with PSS 3\% and 5\%. It also can be seen from Table 3 and Figure 10 that the $R$ value is mainly improved within the first 3 hours of curing time. The photos of reinforcement layers taken from the specimens with curing time $24 \mathrm{~h}$ after the tests are presented in Figure 11. 


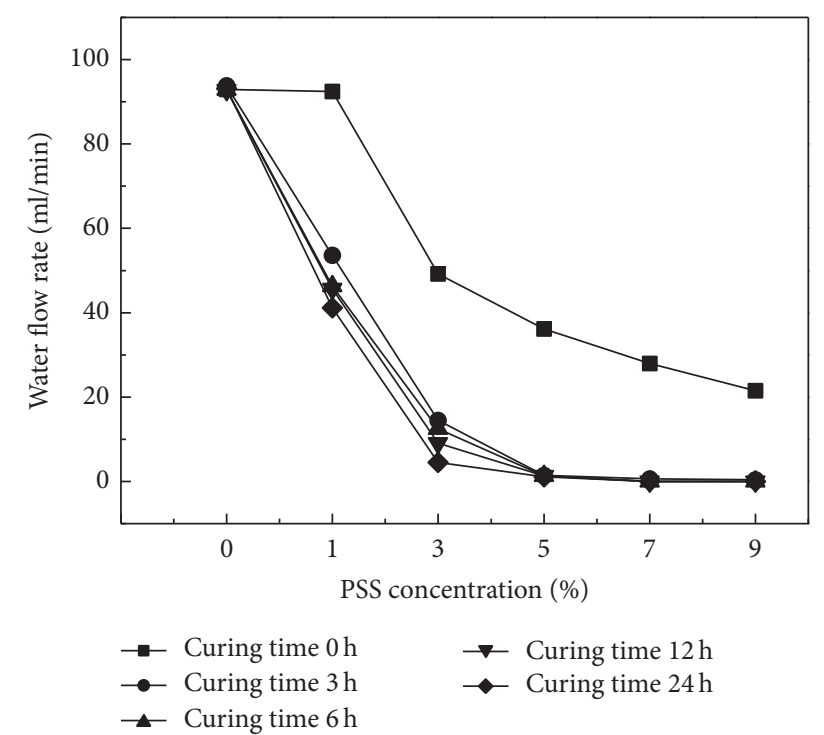

FIgURE 9: Variations of water flow rate $(F)$ of specimens with PSS concentrations at flow time of $12-15 \mathrm{~min}$.

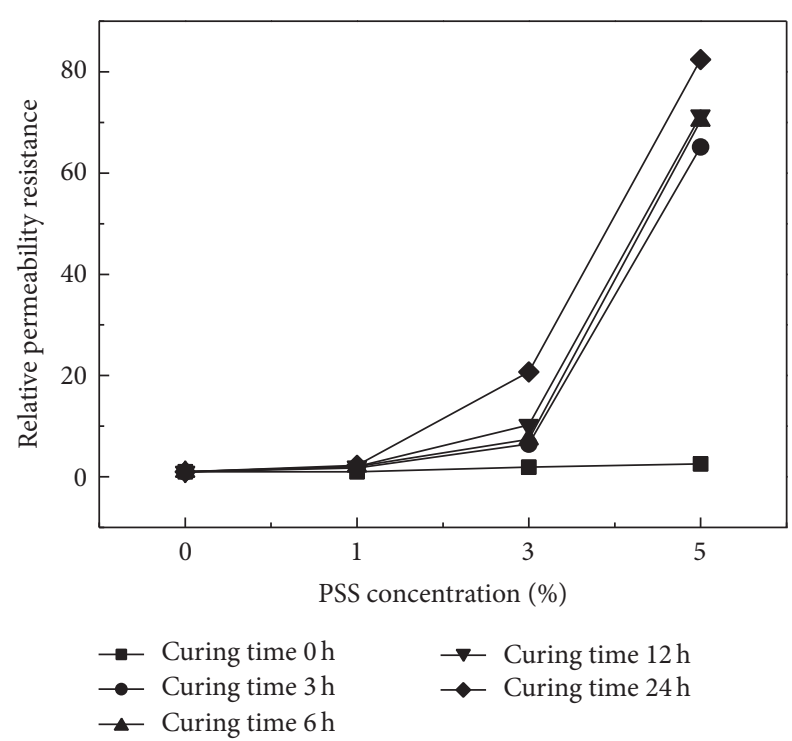

FIGURE 10: The relative permeability resistance $(R)$ of specimens with PSS concentrations of $1 \%, 3 \%$, and $5 \%$ at different curing times.

As seen, the thickness and complete degree of reinforcement layer taken from the surface of specimens with curing time $24 \mathrm{~h}$ increase with the increasing of PSS concentration. The reinforcement layers of specimens with PSS $1 \%, 3 \%$, and $5 \%$ are states of being loose, less completed, and completed, respectively. The ones of specimens with PSS 7\% and 9\% have excellent complete degrees to form the water-resisting layer on sand surface.

3.3. Porous Permeability Test. In porous permeability test, the specimens reinforced with PSS $0 \%, 1 \%, 3 \%$, and $5 \%$ at curing time of 24 hours were considered to study the influence depth of sand surface reinforcement. The initial times of water

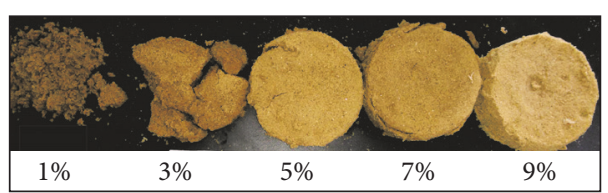

FIGURE 11: Photos of reinforcement layers taken from the specimens with curing time of $24 \mathrm{~h}$ after single-hole permeability tests.

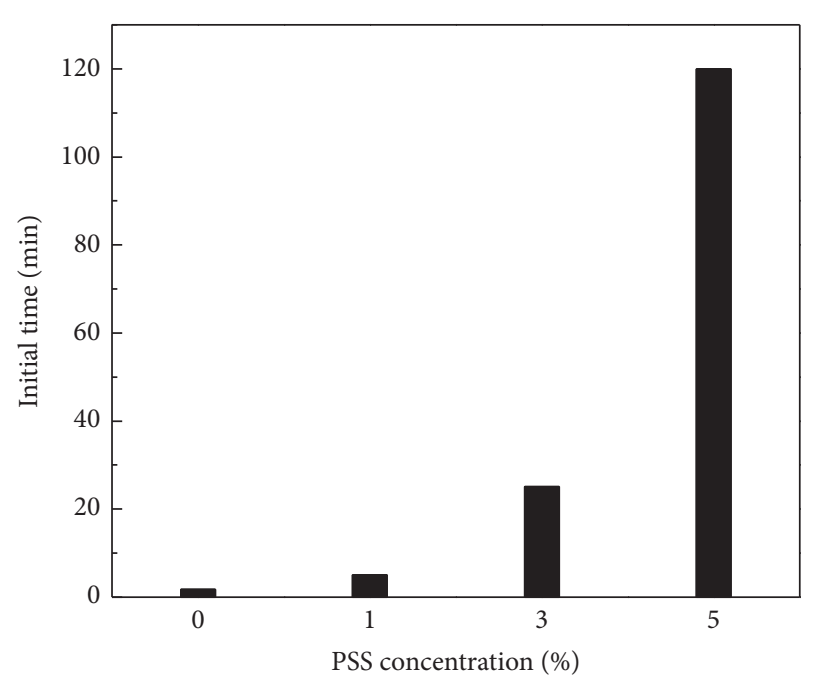

FIGURE 12: Initial time of running water from outlet number 9 of specimens with different PSS concentrations.

running from the outlet tube number 9 and the running water volume of outlet tubes numbers 1 to 9 of every 3 minutes with a number of 5 times were recorded. The test results are presented in Table 4 . The initial times of running water from outlet tube number 9 of specimens with different PSS concentrations are given in Figure 12. As seen in Figure 12, the presence of PSS increased the initial time of water running from number 9 of specimens, especially for PSS 3\% and $5 \%$. The time of water flow from surface to $90 \mathrm{~cm}$ depth of specimens with PSS $3 \%$ and $5 \%$ reaches up to $25 \mathrm{~min}$ and $120 \mathrm{~min}$, respectively.

Based on the data of water volumes in Table 4, the water flow rate $(F)$ of specimens is calculated with (1). The $F$ values of different depth in specimens reinforced with different PSS concentrations of $0 \%, 1 \%, 3 \%$, and $5 \%$ are presented in Figure 13. It can be seen from Figures 13(a) and 13(b) that the $F$ values of depth $90 \mathrm{~cm}$ in specimens unreinforced and reinforced with PSS 1\% quickly reach the stable values, except that the ones of depth $90 \mathrm{~cm}$ reach the stable values after water flow time larger $3 \mathrm{~min}$ and $9 \mathrm{~min}$, respectively. As seen in Figures 13(c) and 13(d), the $F$ values of specimens reinforced with PSS 3\% and 5\% increase with the water flow time at the start period of 0-6 min; after that, it approximately trends to be stable. It also can be seen from Figure 13 that the $F$ values of specimens are affected strongly by PSS concentrations and decrease with the increasing of PSS concentration, especially for higher PSS concentrations of 3\% and 5\%. And all the specimens reach a stable value at the stage of $12-15 \mathrm{~min}$, and 
TABLE 4: Results of porous permeability test.

\begin{tabular}{|c|c|c|c|c|c|c|c|c|}
\hline Number & $\begin{array}{l}\text { PSS con- } \\
\text { centrations } \\
(\%)\end{array}$ & $\begin{array}{l}\text { Sand depth } \\
\quad(\mathrm{cm})\end{array}$ & $\begin{array}{l}\text { Initial time } \\
\qquad(\mathrm{s})\end{array}$ & $\begin{array}{l}\text { Water volume of } \\
0-3 \min (\mathrm{ml})\end{array}$ & $\begin{array}{l}\text { Water volume of } \\
3-6 \min (\mathrm{ml})\end{array}$ & $\begin{array}{l}\text { Water volume of } \\
6-9 \min (\mathrm{ml})\end{array}$ & $\begin{array}{l}\text { Water volume of } \\
9-12 \min (\mathrm{ml})\end{array}$ & $\begin{array}{l}\text { Water volume of } \\
12-15 \mathrm{~min}(\mathrm{ml})\end{array}$ \\
\hline \multirow{9}{*}{ P-1 } & $0 \%$ & 90 & 108 & 163.58 & 1152.47 & 1158.19 & 1164.67 & 1152.22 \\
\hline & $0 \%$ & 80 & 1 & 1113.69 & 1119.76 & 1110.97 & 1115.56 & 1122.39 \\
\hline & $0 \%$ & 70 & I & 1018.21 & 1081.89 & 1037.63 & 1047.71 & 1059.72 \\
\hline & $0 \%$ & 60 & I & 858.27 & 871.75 & 864.56 & 853.86 & 854.19 \\
\hline & $0 \%$ & 50 & I & 724.82 & 733.72 & 718.24 & 720.44 & 786.06 \\
\hline & $0 \%$ & 40 & I & 699.01 & 710.60 & 677.15 & 702.00 & 697.38 \\
\hline & $0 \%$ & 30 & I & 698.38 & 676.47 & 692.47 & 691.87 & 695.30 \\
\hline & $0 \%$ & 20 & I & 501.95 & 508.12 & 486.43 & 469.03 & 489.07 \\
\hline & $0 \%$ & 10 & 1 & 365.28 & 419.73 & 392.43 & 383.27 & 388.21 \\
\hline \multirow{9}{*}{ P-2 } & $1 \%$ & 90 & 305 & 147.07 & 277.42 & 989.39 & 1062.42 & 1041.25 \\
\hline & $1 \%$ & 80 & 1 & 885.82 & 865.74 & 866.86 & 880.41 & 881.39 \\
\hline & $1 \%$ & 70 & I & 753.78 & 762.15 & 755.60 & 777.70 & 773.99 \\
\hline & $1 \%$ & 60 & I & 749.71 & 754.97 & 747.34 & 758.36 & 758.73 \\
\hline & $1 \%$ & 50 & I & 743.83 & 734.2 & 726.61 & 737.77 & 707.91 \\
\hline & $1 \%$ & 40 & I & 570.61 & 569.03 & 562.11 & 553.26 & 554.50 \\
\hline & $1 \%$ & 30 & I & 568.32 & 574.71 & 584.79 & 544.77 & 549.69 \\
\hline & $1 \%$ & 20 & I & 413.01 & 395.92 & 398.83 & 392.69 & 393.34 \\
\hline & $1 \%$ & 10 & 1 & 282.60 & 293.46 & 307.17 & 286.12 & 289.92 \\
\hline \multirow{9}{*}{ P-3 } & $3 \%$ & 90 & 1505 & 72.13 & 329.33 & 360.59 & 360.39 & 363.18 \\
\hline & $3 \%$ & 80 & I & 245.77 & 334.64 & 350.96 & 357.55 & 359.86 \\
\hline & $3 \%$ & 70 & I & 188.36 & 292.52 & 324.62 & 348.77 & 350.26 \\
\hline & $3 \%$ & 60 & I & 217.59 & 303.63 & 328.66 & 346.53 & 337.17 \\
\hline & $3 \%$ & 50 & I & 219.46 & 296.48 & 326.05 & 338.52 & 323.58 \\
\hline & $3 \%$ & 40 & I & 269.97 & 301.23 & 319.64 & 313.52 & 321.66 \\
\hline & $3 \%$ & 30 & I & 234.20 & 267.63 & 278.76 & 292.08 & 293.12 \\
\hline & $3 \%$ & 20 & I & 197.11 & 213.06 & 216.26 & 213.55 & 214.65 \\
\hline & $3 \%$ & 10 & 1 & 128.55 & 129.40 & 148.07 & 144.43 & 141.15 \\
\hline \multirow{9}{*}{ P-4 } & $5 \%$ & 90 & 7200 & 17.19 & 35.50 & 33.24 & 33.46 & 34.26 \\
\hline & $5 \%$ & 80 & 1 & 16.75 & 30.07 & 31.74 & 32.34 & 33.75 \\
\hline & $5 \%$ & 70 & I & 15.72 & 30.72 & 32.75 & 32.76 & 32.96 \\
\hline & $5 \%$ & 60 & I & 14.36 & 29.61 & 30.48 & 30.19 & 32.41 \\
\hline & $5 \%$ & 50 & I & 14.61 & 29.69 & 29.13 & 28.58 & 28.33 \\
\hline & $5 \%$ & 40 & I & 12.88 & 28.64 & 28.25 & 27.58 & 27.78 \\
\hline & $5 \%$ & 30 & I & 10.89 & 24.42 & 26.34 & 26.49 & 25.97 \\
\hline & $5 \%$ & 20 & I & 10.36 & 21.02 & 23.04 & 22.27 & 22.83 \\
\hline & $5 \%$ & 10 & 1 & 8.62 & 19.16 & 18.53 & 18.43 & 18.93 \\
\hline
\end{tabular}

the $F$ values at $12-15 \mathrm{~min}$ are considered as parameters to evaluate the permeability resistance of different depths in specimens reinforced with PSS.

The variations of water flow rate $(F)$ of different depths in specimens at flow time $12-15$ min are presented in Table 5 and Figure 14. As seen, the $F$ values of every depth in specimens decrease with the increasing of PSS concentration. The $F$ values of specimens unreinforced and reinforced with PSS 1\% gradually increase with the increasing of depth. The $F$ values of one reinforced with PSS 3\% increase with the depth during the depth range of $0-40 \mathrm{~cm}$ and then keep a stable value. The $F$ values of one reinforced with higher PSS concentration 5\% are very small and not affected by the depth of specimen. The permeability coefficients $(K)$ of specimens calculated with (2) are shown in Table 6. They have the same change characteristics with the $F$ values. The $K$ values decrease with the increasing of PSS concentration and increase with the increasing of depth in specimen. 


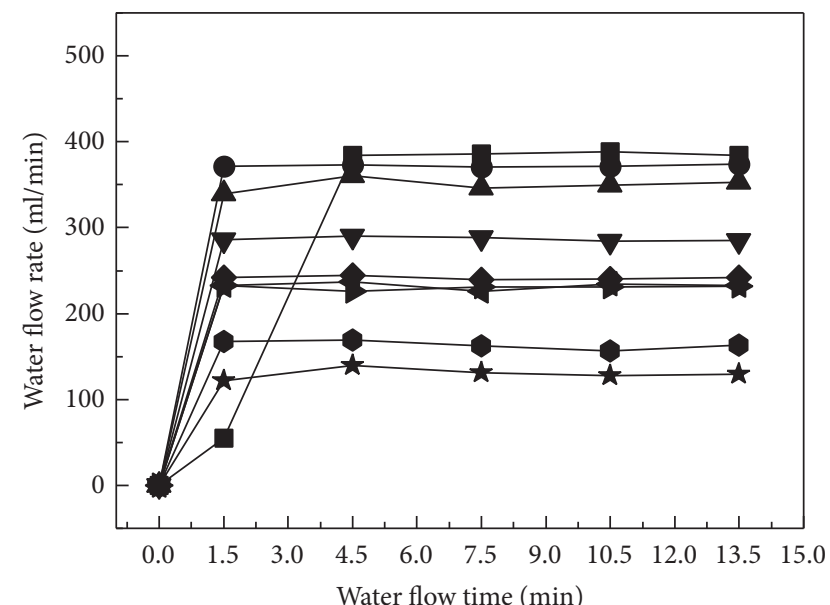

Water flow time ( $\mathrm{min}$ )

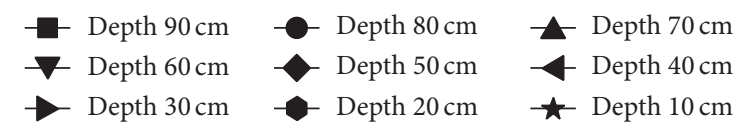

(a) PSS 0\%

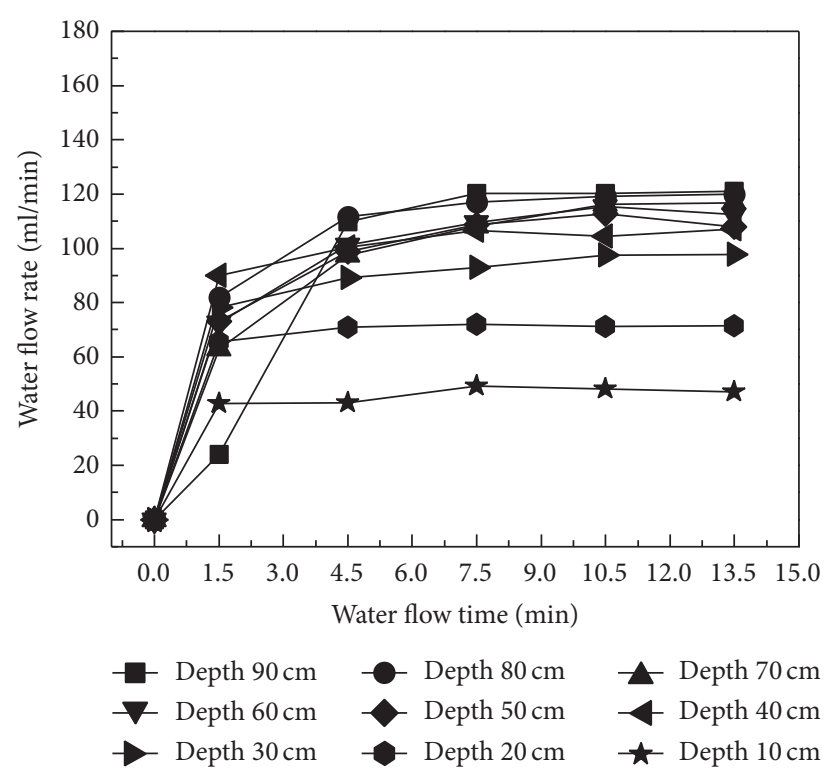

(c) PSS $3 \%$

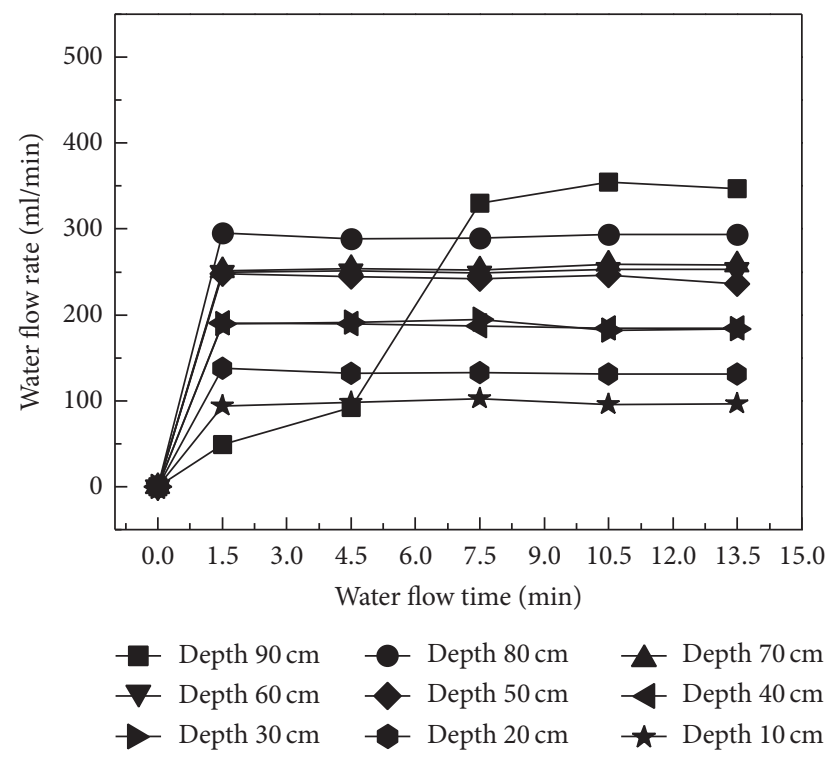

(b) PSS $1 \%$
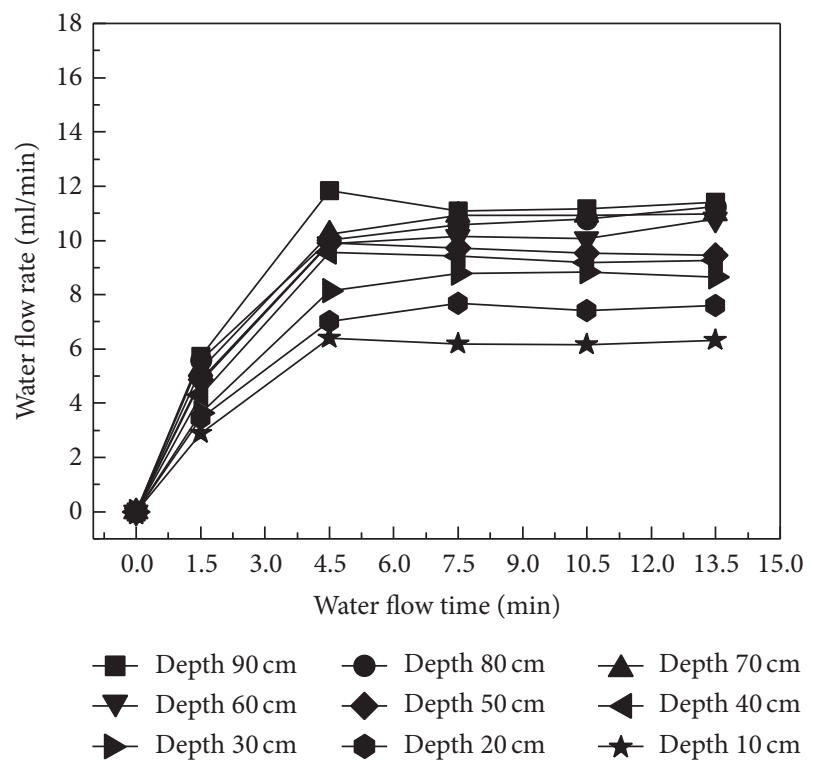

(d) PSS 5\%

FIGURE 13: The water flow rate $(F)$ of different depth in specimens reinforced with different PSS concentrations.

TABLE 5: The water flow rate at time of $12-15 \mathrm{~min}$ of specimens with different depth $(\mathrm{ml} / \mathrm{min})$.

\begin{tabular}{lcccccccccc}
\hline Number & $\begin{array}{c}\text { PSS concentrations } \\
(\%)\end{array}$ & 90 & 80 & 70 & 60 & 50 & 40 & 30 & 20 \\
\hline G-1 & 0 & 384.07 & 374.13 & 353.24 & 284.73 & 262.02 & 232.46 & 231.77 & 163.02 & 129.4 \\
G-2 & 1 & 347.08 & 293.8 & 258.00 & 252.91 & 245.97 & 184.83 & 183.23 & 131.11 & 96.64 \\
G-3 & 3 & 121.06 & 119.95 & 116.75 & 112.39 & 107.86 & 107.22 & 97.71 & 71.55 & 47.05 \\
G-4 & 5 & 11.42 & 11.25 & 11.00 & 10.80 & 9.44 & 9.26 & 8.66 & 7.61 & 6.31 \\
\hline
\end{tabular}




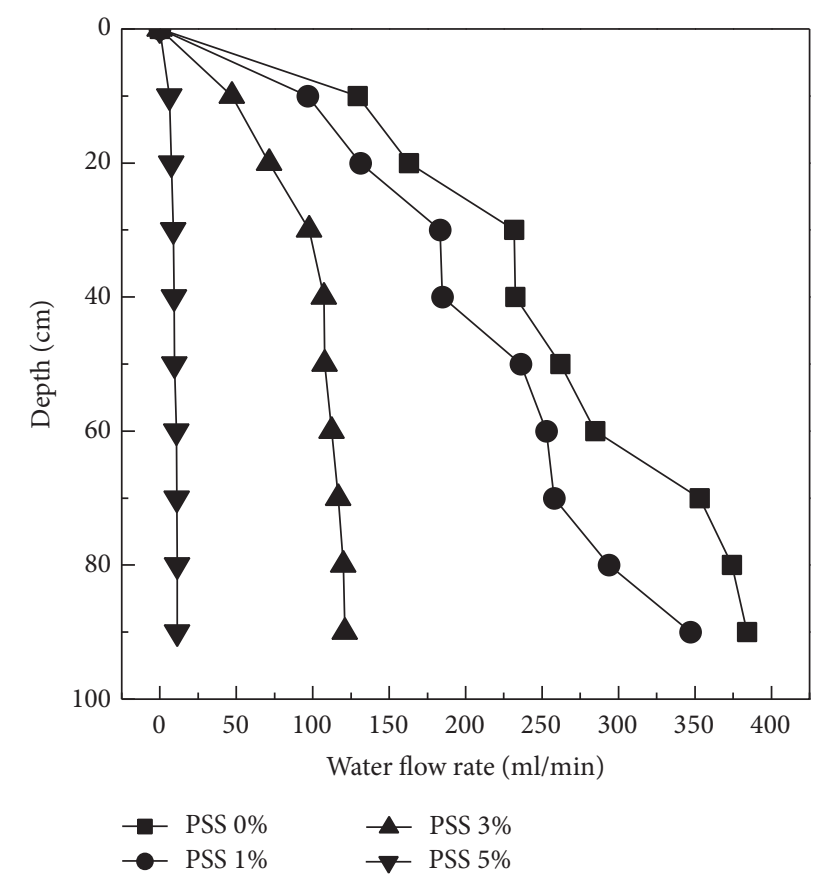

Figure 14: Variations of water flow rate $(F)$ of different depths in specimens at flow time of $12-15 \mathrm{~min}$.

The relative permeability resistance $(R)$ calculated with (3) is shown in Table 7 . As seen, the relative permeability resistance of each depth of reinforced specimens with curing time of 24 hours is improved. The $R$ values of the specimens are mainly affected by the PSS concentration, especially for the specimen with PSS 5\%. The $R$ values of specimen with depth of $10 \mathrm{~cm}, 30 \mathrm{~cm}, 60 \mathrm{~cm}$, and $90 \mathrm{~cm}$ are 20.51, 26.76, 26.36 , and 33.63, respectively. The photos of reinforcement layers taken from the specimens with curing time of $24 \mathrm{~h}$ after the porous permeability tests are presented in Figure 15. As seen, the thickness and complete degree of reinforcement layer taken from the surface of specimens increase with the increasing of PSS concentration. The reinforcement layers of specimens with PSS 1\%, 3\% and 5\% are states of being loose, less completed, and completed, respectively.

\section{Discussion}

The polyurethane soil stabilizer (PSS) contains a significant proportion of the long-chain macromolecule of polyurethane resin and enormous amount of isocyanate group (-NCO). The structural formula of PSS is represented by formula (4) and its reinforcement reaction process is represented by formulas (5) and (6). When PSS solution is diluted and sprayed on sand, a part fills up the voids of sand and others adsorb on the surface of sand particle. The active groups -NCO in formula (4) react with water in voids and on surface of sand through chemical formulas (5) and (6) to form the reinforcement layer. These reactions create physicochemical bonds between molecules and sand particle. With these bonds, the PSS enwrap the sand particles and interlink them to form a reinforcement layer on the sand surface. The SEM images of specimen reinforced with PSS $5 \%$ are presented in Figure 16. As seen in Figures 16(a)-16(d), the sand particles are enwrapped and connected by the PSS to form a stable structure. This structure may increase in bonding and interlocking forces between sand particles and decrease the void ratio of sand.

$$
\begin{aligned}
& \mathrm{O}=\mathrm{C}=\mathrm{N}-\left[\begin{array}{cc}
\mathrm{H} & \mathrm{O} \\
\mathrm{I} & \mathrm{R} \\
\mathrm{N} & -\mathrm{C}-\mathrm{O}-\mathrm{R}_{2}-\mathrm{O}-\mathrm{II} \\
\mathrm{II} & -\mathrm{N} \\
\mathrm{O} & \mathrm{I}
\end{array}\right]_{n} \mathrm{R}_{1}-\mathrm{N}=\mathrm{C}=\mathrm{O}
\end{aligned}
$$

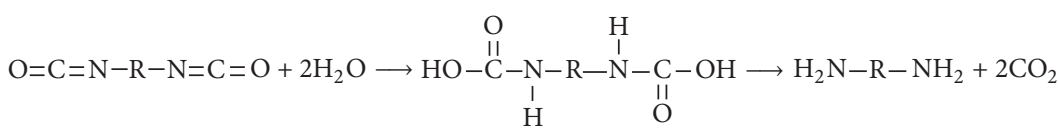

$$
\begin{aligned}
& \left.(n+1) \mathrm{H}_{2} \mathrm{~N}-\mathrm{R}-\mathrm{NH}_{2}+n \mathrm{O}=\mathrm{C}=\mathrm{N}-\mathrm{R}-\mathrm{N}=\mathrm{C}=\mathrm{O} \longrightarrow \underset{\mathrm{H}}{2} \mathrm{~N}-\mathrm{R}-\stackrel{\mathrm{H}}{\mathrm{N}}-\underset{\mathrm{O}}{\mathrm{C}}-\stackrel{\mathrm{H}}{\mathrm{N}}\right]_{2 n}-\mathrm{NH}_{2} .
\end{aligned}
$$

The specimen surface is sprayed by PSS dilution to form the reinforcement layer. The curing time and dilution concentration are two important factors to the formation of reinforcement layer on specimen surface. This forming process requires a certain amount of curing time. This is the reason why the thickness of reinforcement layer reaches a stable value when the curing time is larger than 3 hours (see Figure 6). The higher PSS concentration, the more content of long-chain macromolecule to fill the sand voids and enwrap the sand particles with a resultant increase of the thickness of reinforcement layer on specimen surface (see Figure 6). And the complete degree of reinforcement layer taken from the surface of specimens also increases with the increasing of PSS concentration (see Figures 11 and 15). The sand voids filled with PSS reduce or block the flowing channels of water, resulting in the fact that the time in which water flow passes through the reinforcement layer from the surface of specimen is increased. This permeability time of reinforcement layer increases with the PSS concentration (see Figures 7 and 12). 
TABLE 6: The permeability coefficient of specimens with different depth $(\mathrm{cm} / \mathrm{s})$.

\begin{tabular}{lcccccccccc}
\hline Number & $\begin{array}{c}\text { PSS concentrations } \\
(\%)\end{array}$ & 90 & 80 & 70 & 60 & 50 & 40 & 30 & 20 & 10 \\
\hline G-1 & 0 & $1.93 E-2$ & $1.87 E-2$ & $1.75 E-2$ & $1.40 E-2$ & $1.26 E-2$ & $1.10 E-2$ & $1.05 E-2$ & $6.92 E-3$ & $4.58 E-3$ \\
G-2 & 1 & $1.75 E-2$ & $1.47 E-2$ & $1.28 E-2$ & $1.24 E-2$ & $1.19 E-2$ & $8.72 E-3$ & $8.33 E-3$ & $5.57 E-3$ & $3.42 E-3$ \\
G-3 & 3 & $6.09 E-3$ & $5,99 E-3$ & $5.78 E-3$ & $5.51 E-3$ & $5.20 E-3$ & $5.05 E-3$ & $4.45 E-3$ & $3.04 E-3$ & $1.66 E-3$ \\
G-4 & 5 & $5.74 E-4$ & $5.62 E-4$ & $5.45 E-4$ & $5.29 E-4$ & $4.55 E-4$ & $4.37 E-4$ & $3.94 E-4$ & $3.23 E-4$ & $2.23 E-4$ \\
\hline
\end{tabular}

TABLE 7: The relative permeability resistance of specimens with different depth.

\begin{tabular}{lcccccccccc}
\hline Number & $\begin{array}{c}\text { PSS concentrations } \\
(\%)\end{array}$ & 90 & 80 & 70 & 60 & 50 & 40 & 30 & 20 \\
\hline G-1 & 0 & 1 & 1 & 1 & 1 & 1 & 1 & 1 & 1 \\
G-2 & 1 & 1.11 & 1.27 & 1.37 & 1.13 & 1.07 & 1.26 & 1.26 & 1.24 & 1.34 \\
G-3 & 3 & 3.17 & 3.12 & 3.03 & 2.53 & 2.43 & 2.17 & 2.37 & 2.28 & 2.75 \\
G-4 & 5 & 33.63 & 33.26 & 32.11 & 26.36 & 27.76 & 25.10 & 26.76 & 21.42 & 20.51 \\
\hline
\end{tabular}

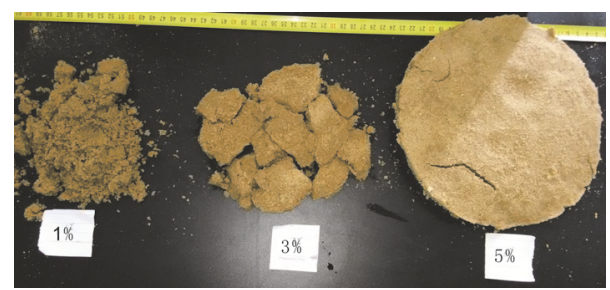

FIGURE 15: Photos of reinforcement layers taken from the specimens with curing time of $24 \mathrm{~h}$ after the porous permeability tests.

The flowing water rate of reinforcement layer on specimen surface reduces with the decreasing of its void radio. This decrement of void radio is improved by the curing time or PSS concentration. The flowing water rate of tested part of sand is mainly controlled by the sand layer with lowest void radio. So the flowing water rate decreases with the increase in curing time or PSS concentration (see Figures 8,9 , and 13). While there is lower PSS concentration or shorter curing time, there is not enough macromolecule or time to form the reinforcement layer. Therefore, the relative permeability resistances of specimens were mainly improved with the curing time larger than 3 hours and PSS concentrations higher than 3\% (see Figure 10 and Table 7). The water-resisting layer on sand surface is formed with the curing time and PSS concentration larger than 6 hours and $7 \%$, respectively. The upper limit of PSS concentration for improving the antipermeability of sand is $9 \%$, due to its good water-resisting layer on sand surface.

As seen in Figure 16, the polymers enwrap the sand particle's surface and interlink them to form an elastic and viscous cover on the sand surface to improve the interlocking forces between sand particles. This void filling and physicochemical bonding may lead to a resulting improvement in the mechanical properties such as compressive strength, tensile strength, erosion resistance, and cohesion of sand. This paper is only limited to evaluate the effect of PSS on the permeability characteristics of sand with the particle size of $0.1-1 \mathrm{~mm}$. The results indicated that the curing time and PSS concentration are important consideration factors in reinforcing process. While the PSS is used to improve different mechanical properties, sand content, and soil particle size, reinforcement method, curing time, and optimal concentration should be adjusted to meet the different engineering requirements in practical application.

PSS is a kind of waterborne polyurethane polymer and a form of oil liquid. When polymer as a reinforcing material is used in practical engineering, the environmental concerns must be taken seriously. The potential environmental concerns are mainly because of volatile organic compounds (VOC) and residual PSS solution, which will cause air pollution and water resource pollution. In order to reduce or avoid the environmental concerns, the VOC of PSS must be strictly controlled according to international regulations; the residual PSS solution must be recycled with effective methods. The sunny day should be selected for spraying PSS in field to ensure sufficient reaction of polymer and sand particle to reduce the polymer loss and water pollution.

The aging degradation of polymer is mainly affected by temperature, ultraviolet ray, water, and chemical mediator. Reactions (5) and (6) during the reinforcement process of PSS are not reversible. The reinforcement layer on sand will be damaged due to the aging degradation of polymer. The running water channel formed in reinforcement layer will lead to increase in the permeability of reinforced sand. The durability of PSS on permeability characteristics of sand with the condition temperature $-10 \sim 50^{\circ} \mathrm{C}$, ultraviolet intensity $\leq$ $250 \mathrm{~mW} / \mathrm{m}^{2}$, and no chemical mediator is about 10 years. However, while the PSS is applied in engineering area with 


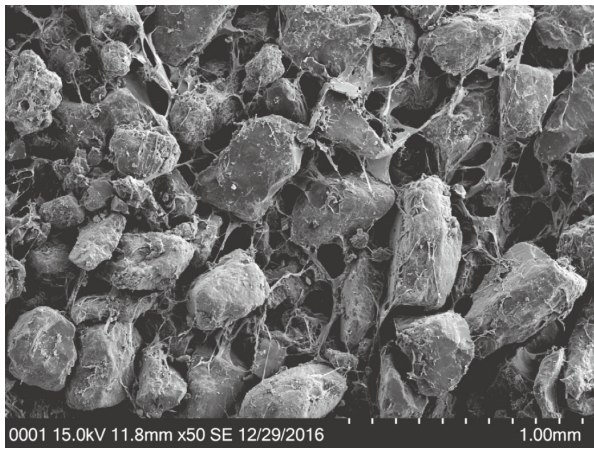

(a)

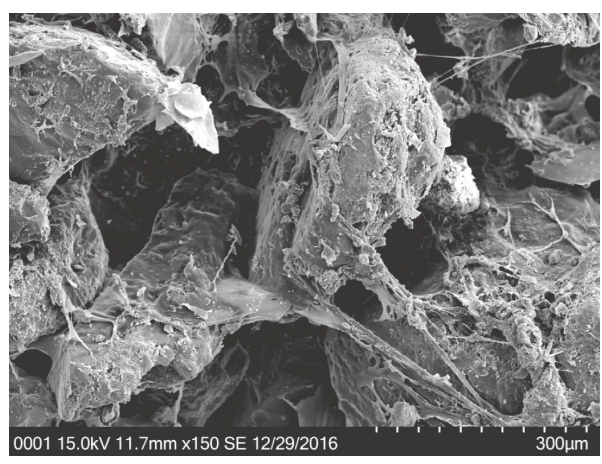

(c)

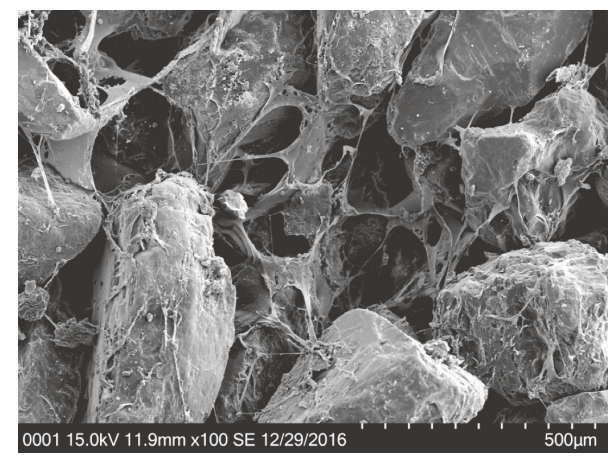

(b)

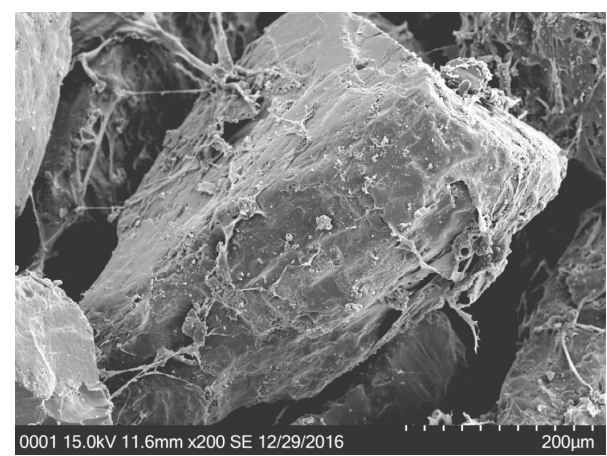

(d)

FIGURE 16: SEM images of specimen reinforced with PSS 5\%: (a) 50 times magnification, (b) 100 times magnification, (c) 150 times magnification, and (d) 200 times magnification.

extreme weather, high ultraviolet intensity, or polluted soil, the long term effects of polymer on permeability characteristics will be shortened.

\section{Conclusions}

In order to evaluate the permeability characteristics of PSS reinforced sand, the laboratory tests of reinforcement layer form test, single-hole permeability test, and porous permeability test were considered. The test results and reinforcement mechanism were analyzed. Based on the results of the tests presented herein, the main conclusions can be summarized as follows:

(1) The permeability resistance of sand reinforced with polyurethane soil stabilizer (PSS) is improved through the formation of reinforcement layer on the sand surface. The thickness and complete degree of the reinforcement layer increase with the increasing of curing time and PSS concentration. The reinforcement layer thicknesses of specimens modified by concentrations of $3 \%, 5 \%, 7 \%$, and $9 \%$ with curing time of $24 \mathrm{~h}$ were approximately $2.12,2.57,3.05$, and $3.56 \mathrm{~cm}$, respectively.

(2) Laboratory tests of single-hole permeability test and porous permeability test indicated that the permeability time of reinforcement layer increases with the
PSS concentration. The flowing water rate decreases with the increasing of curing time or PSS concentration. The permeability coefficient decreases with the increasing of curing time and PSS concentration and increases with the increasing of depth in specimen. The relative permeability resistances of specimens were mainly improved with the curing time larger than 3 hours and PSS concentrations higher than 3\%. The water-resisting layer on sand surface is formed with the curing time and PSS concentration larger than 6 hours and 7\%, respectively.

(3) The PSS contains a significant proportion of the long-chain macromolecule of polyurethane resin and enormous amount of isocyanate group (-NCO). Microscale SEM observations show that the PSS enwrap the sand particle and interlink them to form a reinforcement layer on the sand surface. PSS fills up the voids of sand and adsorbs on the surface of sand particle to reduce or block the flowing channels of water to improve the permeability resistance of sand. The results can be applied as the reference for PSS reinforced sand engineering, especially for surface protection of embankment, slope, and landfill. The reinforcement method, curing time, and optimal concentration should be adjusted to meet the different engineering requirements in practical applications. 


\section{Conflicts of Interest}

The authors declare that there are no conflicts of interest regarding the publication of this paper.

\section{Acknowledgments}

This research was financially supported by the National Natural Science Foundation of China (Grants nos. 41472241 and 41202208) and Natural Science Foundation of Jiangsu Province, China (Grant no. BK20141415).

\section{References}

[1] C. Ghosh and K. Yasuhara, "Clogging and flow characteristics of a geosynthetic drain confined in soils undergoing consolidation," Geosynthetics International, vol. 11, no. 1, pp. 19-34, 2004.

[2] C. Yoo and H.-Y. Jung, "Case history of geosynthetic reinforced segmental retaining wall failure," Journal of Geotechnical and Geoenvironmental Engineering, vol. 132, no. 12, pp. 1538-1548, 2006.

[3] D. V. Raisinghani and B. V. S. Viswanadham, "Evaluation of permeability characteristics of a geosynthetic-reinforced soil through laboratory tests," Geotextiles and Geomembranes, vol. 28, no. 6, pp. 579-588, 2010.

[4] E. M. Palmeira and M. G. Gardoni, "Drainage and filtration properties of non-woven geotextiles under confinement using different experimental techniques," Geotextiles and Geomembranes, vol. 20, no. 2, pp. 97-115, 2002.

[5] K. R. Lekha, "Field instrumentation and monitoring of soil erosion in coir geotextile stabilised slopes-a case study," Geotextiles and Geomembranes, vol. 22, no. 5, pp. 399-413, 2004.

[6] A. Tolooiyan, I. Abustan, M. R. Selamat, and S. Ghaffari, "A comprehensive method for analyzing the effect of geotextile layers on embankment stability," Geotextiles and Geomembranes, vol. 27, no. 5, pp. 399-405, 2009.

[7] U. Smoltczyk and K. Malcharek, "Slope protection by membrane structures," Geotextiles and Geomembranes, vol. 2, no. 4, pp. 323-336, 1985.

[8] N. Pollen, "Temporal and spatial variability in root reinforcement of streambanks: accounting for soil shear strength and moisture," Catena, vol. 69, no. 3, pp. 197-205, 2007.

[9] D. Liu and Y. Li, "Mechanism of plant roots improving resistance of soil to concentrated flow erosion," Journal of Soil and Water Conservation, vol. 17, no. 3, pp. 34-37, 2003.

[10] S. S. Kukal, M. Kaur, S. S. Bawa, and N. Gupta, "Water-drop stability of PVA-treated natural soil aggregates from different land uses," Catena, vol. 70, no. 3, pp. 475-479, 2007.

[11] J. Liu, B. Shi, Y. Lu et al., "Effectiveness of a new organic polymer sand-fixing agent on sand fixation," Environmental Earth Sciences, vol. 65, no. 3, pp. 589-595, 2012.

[12] H. I. Inyang and S. Bae, "Polyacrylamide sorption opportunity on interlayer and external pore surfaces of contaminant barrier clays," Chemosphere, vol. 58, no. 1, pp. 19-31, 2005.

[13] J. Yang, L. Fang, and T. Tan, "Synthesis and characterization of superabsorbent hydrogels composites based on polysuccinimide," Journal of Applied Polymer Science, vol. 102, no. 1, pp. 550-557, 2006.

[14] J. Yang, F. Wang, L. Fang, and T. Tan, "The effects of aging tests on a novel chemical sand-fixing agent-polyaspartic acid,"
Composites Science and Technology, vol. 67, no. 10, pp. 21602164, 2007.

[15] G. Telysheva and G. Shulga, "Silicon-containing polycomplexes for protection against wind erosion of sandy soil," Journal of Agricultural Engineering Research, vol. 62, no. 4, pp. 221-227, 1995.

[16] W. J. Orts, R. E. Sojka, and G. M. Glenn, "Biopolymer additives to reduce erosion-induced soil losses during irrigation," Industrial Crops and Products, vol. 11, no. 1, pp. 19-29, 2000.

[17] Y. Qin, H. Yang, Z. Deng, and J. He, "Water permeability of pervious concrete is dependent on the applied pressure and testing methods," Advances in Materials Science and Engineering, vol. 2015, Article ID 404136, 6 pages, 2015. 

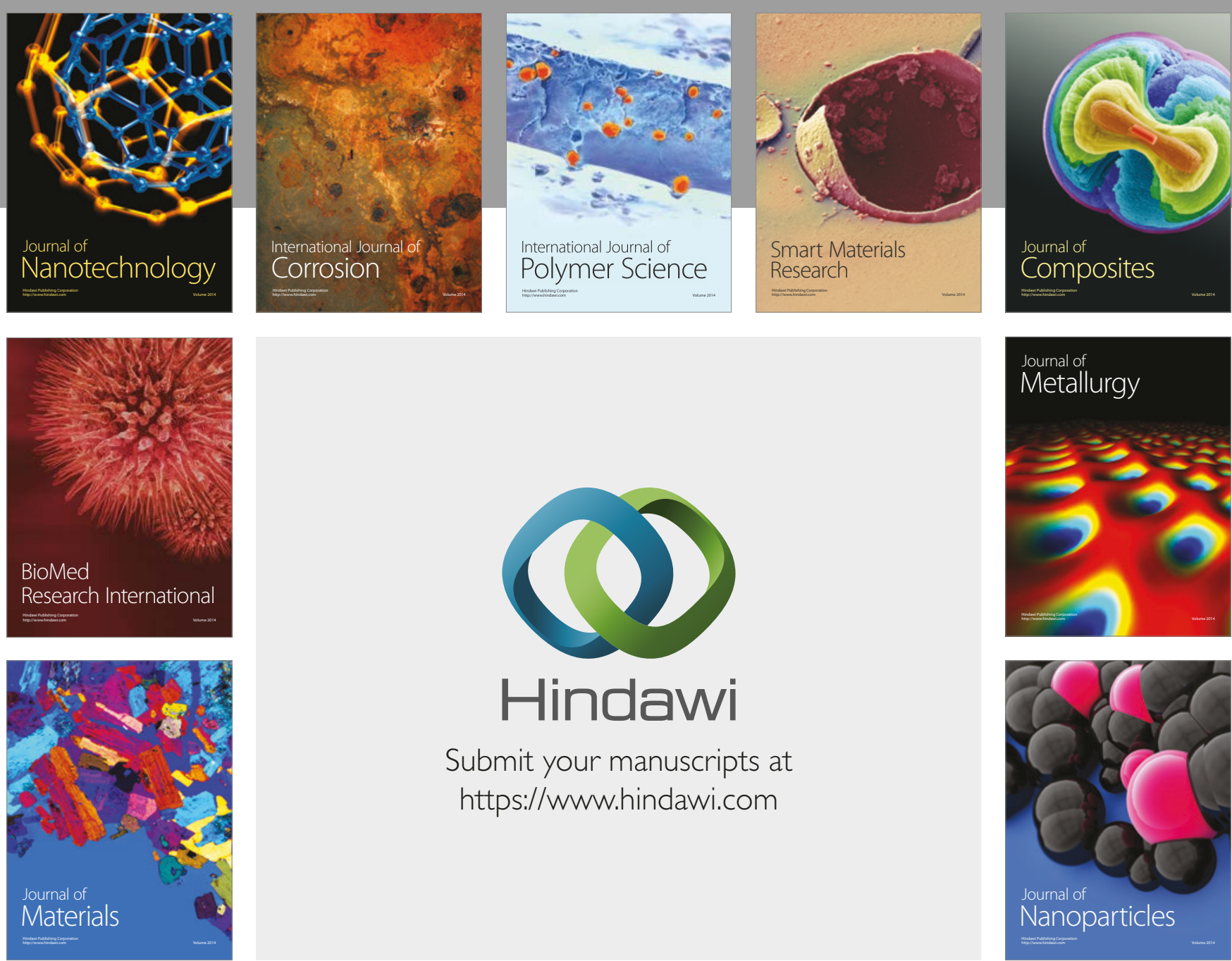

\section{Hindawi}

Submit your manuscripts at

https://www.hindawi.com
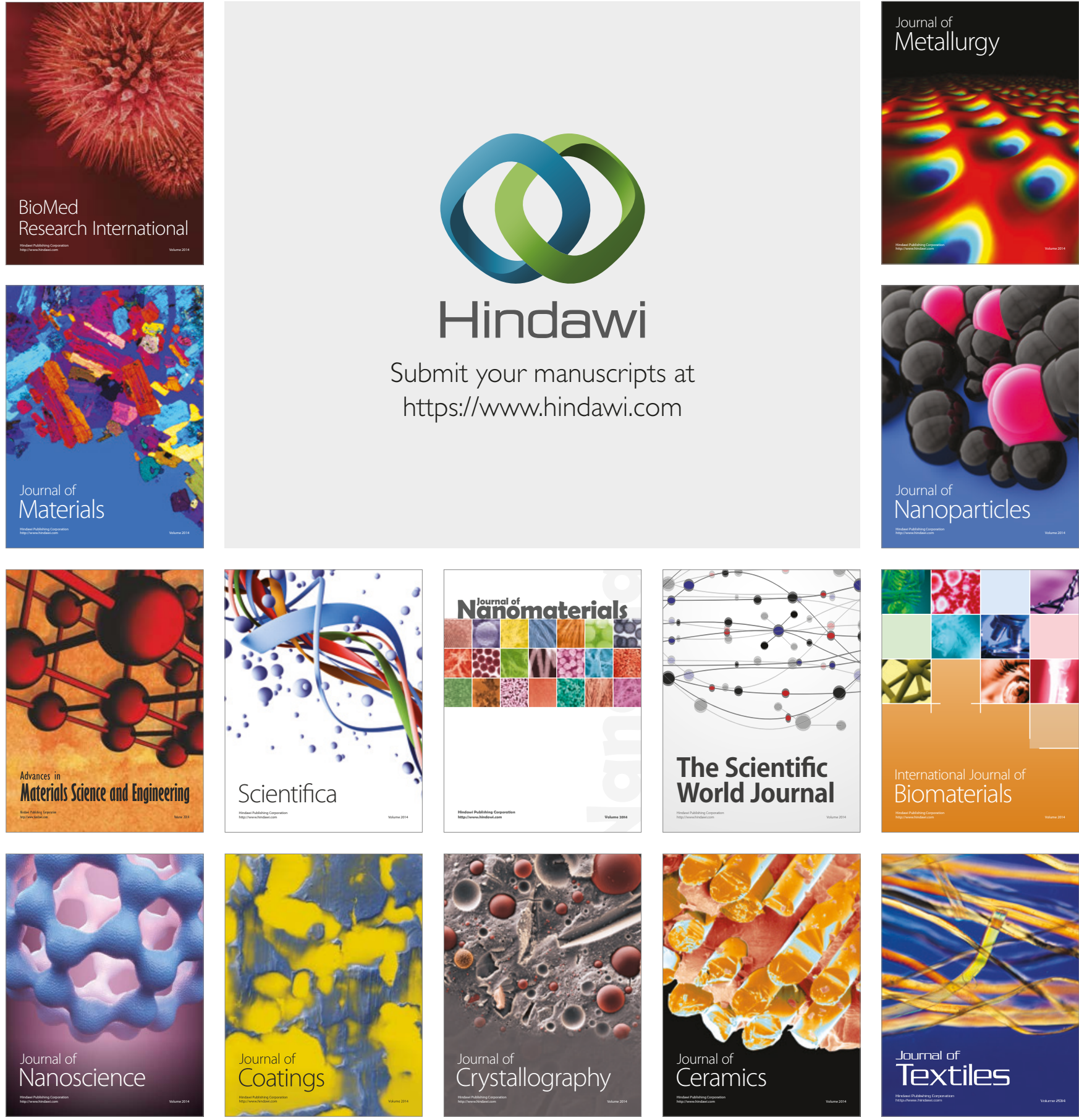

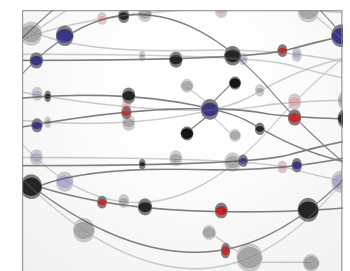

The Scientific World Journal
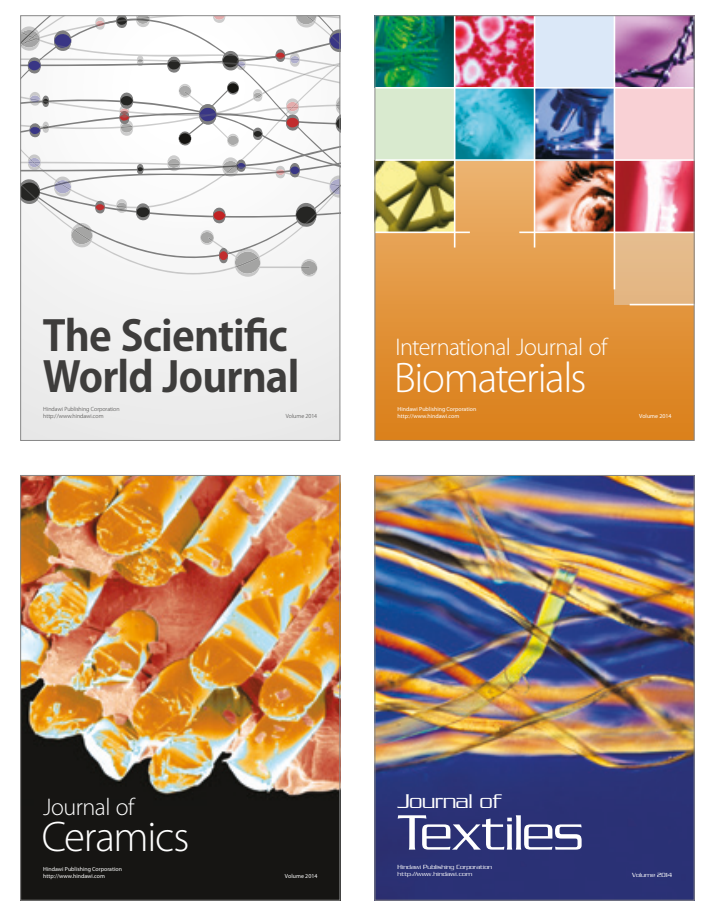